\title{
Effect of Downregulating the Hippo Pathway Members YAP1 and LATS2 Transcripts on Early Development and Gene Expression Involved in Differentiation in Porcine Embryos
}

\author{
Natsuko Emura, ${ }^{1}$ Yuriko Saito, ${ }^{2}$ Ruri Miura, ${ }^{2}$ and Ken Sawai ${ }^{1,2}$
}

\begin{abstract}
In mouse development, differentiation of the inner cell mass (ICM) and trophectoderm (TE) during the transition from the morula to blastocyst stage is regulated by the Hippo pathway; however, the functions of the Hippo pathway in porcine embryogenesis have not been investigated. In the present study, we examined the gene expression patterns of the Hippo pathway members yes-associated protein 1 (YAP1) and large tumor suppressor 2 (LATS2) and the functions of these genes during porcine preimplantation development using RNA interference. Both YAP1 and LATS2 mRNA levels were shown high in the in vitro matured oocytes and 1-cell stage embryos and fell progressively with development. YAP1 nuclear localization was detected at the morula and blastocyst stages. Downregulation of either YAP1 or LATS2 inhibited porcine preimplantation development and affected the expression levels of POU class 5 homeobox 1 (OCT-4) and SRY-related HMG-box gene 2 (SOX2), transcription factors necessary for the ICM/TE differentiation. Taken together, YAP1 and LATS2 are essential for porcine preimplantation development, and it is possible that the Hippo pathway has important roles in porcine ICM/TE segregation.
\end{abstract}

Keywords: embryo, early development, porcine, IVF, Hippo pathway

\section{Introduction}

$\mathbf{T}$ HE FIRST VISIBLE DIFFERENTIATION EVENT during mammalian embryonic development is the segregation of the trophectoderm (TE) and the inner cell mass (ICM) from the morula to blastocyst stage. The TE is an epithelial outer layer that develops into the placenta, whereas the ICM is a group of cells attached to the inside of the TE that gives rise to the fetus and extraembryonic tissues (Pedersen et al., 1986). In mice, ICM and TE can be isolated and maintained in vitro as embryonic stem cells (ESCs) and trophoblast stem cells (TSCs), respectively (Evans and Kaufman, 1981; Martin, 1981; Tanaka et al., 1998). Thus, it is important to elucidate the molecular mechanism of the ICM/TE segregation, which is the starting point of cell differentiation, and it is known that the differentiation requires the precisely timed expression of multiple transcription factors (Yamanaka et al., 2006).

The Hippo pathway controls a number of cellular events such as cell proliferation, cell death, and cell differentiation (Yu et al., 2013; Zhao et al., 2007) and is one of the main regulators of the ICM/TE lineages divergence in murine embryos (Hirate et al., 2013; Nishioka et al., 2009). Activation of the Hippo pathway depends on the cell position in early em- bryos. In the inner cells of murine morulae, the Hippo pathway is activated, allowing the activation of large tumor suppressor 1/2 (Lats 1/2) kinases to phosphorylate yes-associated protein 1 (Yap1) for preventing its nuclear accumulation (Hirate et al., 2013; Nishioka et al., 2009).

As a result, Yap1 transition into nucleus is inhibited, and Yap 1 cannot bind to its partner protein TEA domain transcription factor 4 (Tead4) to drive expression of caudalrelated homeobox $2(C d x 2)$, which is essential for TE segregation (Home et al., 2012; Nishioka et al., 2008, 2009; Rayon et al., 2014; Yagi et al., 2007). And thus, in the absence of Tead4-Yap1 activity, ICM-induced genes such as POU class 5 homeobox 1 (Oct-4) and SRY-related HMGbox gene 2 (Sox2) are expressed in the inner cells (Cockburn et al., 2013; Frum et al., 2018; Lorthongpanich et al., 2013; Wicklow et al., 2014; Yu et al., 2016). In the outer cells, the Hippo pathway is repressed and Lats $1 / 2$ is not activated. Thus, Yap1 is not phosphorylated and can shuttle into the nucleus. Consequently, Yap1 binds to Tead4 and drives $C d x 2$ expression for TE segregation (Nishioka et al., 2009).

We have demonstrated previously that development from the morula to blastocyst stage is inhibited when TEAD4

\footnotetext{
${ }^{1}$ The United Graduate School of Agricultural Sciences, ${ }^{2}$ Faculty of Agriculture, Iwate University, Morioka, Japan.
} 
expression is downregulated by RNA interference in porcine embryos (Emura et al., 2019). In addition, SOX2 transcript levels were increased in these TEAD4-downregulated embryos (Emura et al., 2019). These findings suggest that TEAD4 is needed for TE segregation and that the Hippo pathway controls this function in porcine embryos as in mice. However, roles of the Hippo pathway in porcine embryos have not been investigated in detail.

Moreover, there are evidences for differences in molecular mechanisms of the ICM/TE segregation between mice and pigs. For example, our previous report has demonstrated that OCT-4 is essential for both ICM and TE segregation in porcine embryos, while it is needed only for ICM formation in mice (Emura et al., 2016; Nichols et al., 1998; Sakurai et al., 2013). In addition, CDX2 is dispensable for blastocyst formation in porcine embryos, but not in murine embryos (Bou et al., 2017). Therefore, the molecular mechanisms of the ICM/TE segregation may differ among animal species, and further investigation of YAP1 and large tumor suppressor 2 (LATS2) functions in preimplantation development of porcine embryos is necessitated.

In the present study, we report the functions of the Hippo pathway related genes YAP1 and LATS2 in porcine preimplantation development. First, we characterized expression patterns of YAP1 and LATS2 in porcine oocytes and embryos during progression to the blastocyst stage. We then conducted independent YAP1 and LATS2 knockdown to assess their functions in preimplantation development and gene expression involved in differentiation in porcine embryos.

\section{Materials and Methods}

\section{Chemicals}

All chemicals were purchased from Sigma-Aldrich (St. Louis, MO) unless otherwise stated.

\section{Oocyte collection and in vitro maturation}

Ovaries were collected from prepubertal gilts at a local slaughterhouse and maintained at $37^{\circ} \mathrm{C}$ during transport to the laboratory. Cumulus-oocyte complexes (COCs) were harvested from 2 to $6 \mathrm{~mm}$ diameter follicles in TCM-199 medium supplemented with $10 \%$ (v/v) fetal bovine serum (FBS; Thermo Fisher Scientific, Kanagawa, Japan), 20 mM Hepes, $0.68 \mathrm{mM}$ L-glutamine, $100 \mathrm{IU} / \mathrm{mL}$ penicillin $\mathrm{G}$ potassium (Meiji Seika, Tokyo, Japan), and $0.1 \mathrm{mg} / \mathrm{mL}$ streptomycin sulfate (Meiji Seika).

Approximately $50 \mathrm{COCs}$ with uniform ooplasm and a cumulus cell mass were cultured separately in four-well dishes (Thermo Fisher) for 20 hours in $500 \mu \mathrm{L}$ of maturation medium, composed of a modified North Carolina State University (NCSU)-37 (mNCSU-37) (Petters and Wells, 1993) solution supplemented with $10 \%$ porcine follicular fluid, $0.6 \mathrm{mM}$ cysteine, $0.05 \mathrm{mM} \beta$-mercaptoethanol, $1 \mathrm{mM}$ dibutyryl cAMP (dbcAMP), $10 \mathrm{IU} / \mathrm{mL}$ pregnant mare serum gonadotropin (Serotropin, Aska Animal Health, Tokyo, Japan), and $10 \mathrm{IU} / \mathrm{mL}$ human chorionic gonadotropin (hCG; Gestron 1500, Kyoritsu Seiyaku, Tokyo, Japan). The COCs were subsequently cultured in maturation medium without dbcAMP and hormones for 24 hours. The maturation culture was performed at $39^{\circ} \mathrm{C}$ in a humidified atmosphere of $5 \%$ $\mathrm{CO}_{2}, 5 \% \mathrm{O}_{2}$, and $90 \% \mathrm{~N}_{2}$.

\section{In vitro fertilization and embryo culture}

After in vitro maturation, COCs were washed with modified Pig-FM (mPig-FM) (Kikuchi et al., 2002), and 15-20 COCs were suspended in a $90 \mu \mathrm{L}$ drop of mPig-FM. Cryopreserved semen was thawed, and spermatozoa were washed twice by centrifugation at $1800 \mathrm{rpm}$ for 3 minutes in sperm washing medium (TCM 199 medium supplemented with $20 \mathrm{mM}$ Hepes, $0.68 \mathrm{mM}$ L-glutamine, $100 \mathrm{U} / \mathrm{mL}$ penicillin $\mathrm{G}$ potassium, $0.1 \mathrm{mg} / \mathrm{mL}$ streptomycin sulfate, $0.91 \mathrm{mM}$ sodium pyruvate, $4.12 \mathrm{mM}$ calcium lactate, $3.0 \mathrm{mM}$ glucose, and $10 \%[\mathrm{v} / \mathrm{v}]$ FBS) adjusted to pH 7.8 (Nagai et al., 1988). The spermatozoa were resuspended in sperm washing medium, and $10 \mu \mathrm{L}$ of this suspension was added to $90 \mu \mathrm{L}$ of mPig-FM containing matured COCs. The final concentration of sperm was adjusted to $1.0 \times 10^{6} / \mathrm{mL}$. COCs and sperm were incubated for 6 hours at $39^{\circ} \mathrm{C}$ under a $5 \% \mathrm{CO}_{2}, 5 \% \mathrm{O}_{2}$, and $90 \% \mathrm{~N}_{2}$ atmosphere.

Following microinjection of siRNA, the embryos were washed and cultured in PZM-5 (Suzuki and Yoshioka, 2006) at $39^{\circ} \mathrm{C}$ under a $5 \% \mathrm{CO}_{2}, 5 \% \mathrm{O}_{2}$, and $90 \% \mathrm{~N}_{2}$ atmosphere until day 5 (in vitro fertilization = day 0 ). Rates of embryo development were assessed on day 2 (2-cell $\leq$ stage), day 3 (8-cell stage), day 4 (16-cell $\leq$ and morula stage), and day 5 (blastocyst stage).

\section{Design of siRNA and microinjection into embryos}

The siRNA target sights of the YAP1 and LATS2 transcript were selected from porcine sequences in GenBank (accession nos.: YAP1, XM_021062706.1; LATS2, NM_001177919.1), and specific siRNAs were designed using siRNA design software BLOCK-iT ${ }^{\mathrm{TM}}$ RNAi Designer (http://rnaidesigner .invitrogen.com/rnaiexpress/). Both sense and antisense RNA sequences for siRNAs were commercially synthesized (Table 1).

After insemination, cumulus cells and excess spermatozoa were removed from presumptive zygotes by pipetting. Embryos were subsequently transferred to a $20 \mu \mathrm{L}$ drop of PZM-5. Approximately $10 \mathrm{pL}$ of $50 \mu \mathrm{M}$ specific siRNA duplexes were injected into the cytoplasm of each embryo using a FemtoJet (Eppendorf, Hamburg, Germany). Approximately $10 \mathrm{pL}$ of $20 \mu \mathrm{M}$ nonsilencing siRNA (AllStars Negative Control siRNA; Qiagen, Tokyo, Japan) was injected as a control by the same method. After microinjection, the embryos were cultured as described above.

\section{Determination of gene transcript levels in porcine embryos}

Oocytes and embryos at the indicated developmental stages were treated with $0.1 \%$ protease in $1 \%$ polyvinylpyrrolidone (PVP)-phosphate buffered saline (PBS) for 5 minutes and washed seven times in $1 \%$ PVP-PBS. Pools of 10 (in vitro matured oocytes, 1-cell, 2-4-cell, and 8-16-cell stage embryos) or 5 (morula and blastocyst stage embryos) oocytes or embryos were added to $5 \mu \mathrm{L}$ lysis buffer $(0.8 \%$ Igepal [ICN Biomedicals, Inc., Aurora, OH], $5 \mathrm{mM}$ dithiothreitol [Thermo Fisher], and $1 \mathrm{U} / \mu \mathrm{L}$ of RNasin [Promega, Madison, WI]) and snap-frozen in liquid nitrogen and stored at $-80^{\circ} \mathrm{C}$.

RNA samples were heated to $80^{\circ} \mathrm{C}$ for 5 minutes and treated for reverse transcription (RT) using a QuantiTect Reverse Transcription Kit (Qiagen) according to the manufacturer's instructions. The reaction mixture was diluted 
TABle 1. Primers ANd SiRNA SEQUENCES

\begin{tabular}{|c|c|c|c|c|}
\hline Name & Nucleotide sequences $\left(5^{\prime}-3^{\prime}\right)$ & $\begin{array}{c}\text { Annealing } \\
\text { temperature }(C)\end{array}$ & $\begin{array}{l}\text { Fragment } \\
\text { size }(b p)\end{array}$ & $\begin{array}{c}\text { GenBank } \\
\text { accession no. }\end{array}$ \\
\hline \multirow[t]{2}{*}{$Y A P 1$} & F- ATCAGTCAAAGCGCTCCAGT & \multirow[t]{2}{*}{60} & \multirow[t]{2}{*}{208} & \multirow[t]{2}{*}{ XM_021062706.1 } \\
\hline & R- TTGGAGAATTTGCTGTGCTG & & & \\
\hline \multirow[t]{2}{*}{ LATS2 } & F- TACCAGAAAGGGAGCCACAC & \multirow[t]{2}{*}{60} & \multirow[t]{2}{*}{239} & \multirow[t]{2}{*}{ NM_001177919.1 } \\
\hline & R- AAGAGAATCACGCCGACACT & & & \\
\hline \multirow[t]{2}{*}{$S O X 2$} & F- GCCCTGCAGTACAACTCCAT & \multirow[t]{2}{*}{60} & \multirow[t]{2}{*}{216} & \multirow[t]{2}{*}{ EU503117.1 } \\
\hline & R- GCTGATCATGTCCCGTAGGT & & & \\
\hline \multirow[t]{2}{*}{$O C T-4$} & F- GTTCTCTTTGGGAAGGTGTT & \multirow[t]{2}{*}{55.4} & \multirow[t]{2}{*}{313} & \multirow[t]{2}{*}{ NM_001113060 } \\
\hline & R- ACACGCGGACCACATCCTTC & & & \\
\hline \multirow[t]{2}{*}{$G A P D H$} & F- TCGGAGTGAACGGATTTG & \multirow[t]{2}{*}{52} & \multirow[t]{2}{*}{219} & \multirow[t]{2}{*}{ AF017079 } \\
\hline & R- CCTGGAAGATGGTGATGG & & & \\
\hline \multirow[t]{2}{*}{ YAP1 siRNA } & S- GCUCAUUCCUCUCCAGCUUTT & N/A & N/A & N/A \\
\hline & AS- AAGCUGGAGAGGAAUGAGCTT & N/A & N/A & N/A \\
\hline \multirow[t]{2}{*}{ LATS2 siRNA } & S- GGAAGAUCCUCUACCAGAATT & N/A & N/A & N/A \\
\hline & AS- UUCUGGUAGAGGAUCUUCCTT & N/A & N/A & N/A \\
\hline
\end{tabular}

AS, antisense strand; F, forward; GAPDH, glyceraldehyde-3-phosphate dehydrogenase; LATS2, large tumor suppressor 2; N/A, not applicable; OCT-4, POU class 5 homeobox 1; R, reverse; S, sense strand; SOX2, SRY-related HMG-box gene 2; YAP1, yes-associated protein 1.

with DEPC-treated water to obtain a final volume of $21 \mu \mathrm{L}$. Real-time PCRs were performed using a StepOne ${ }^{\mathrm{TM}}$ system (Applied Biosystems, Tokyo, Japan), and products were detected with SYBR Green included in the QuantiTect SYBR Green PCR master mix (Qiagen).

A $2 \mu \mathrm{L}$ aliquot of the RT product was used for each quantification. The amplification program was as follows: preincubation at $95^{\circ} \mathrm{C}$ for 15 minutes to activate HotStarTaq DNA Polymerase (Qiagen), followed by 45 cycles of denaturation at $94^{\circ} \mathrm{C}$ for 15 seconds, annealing of primers at different temperatures (Table 1) for 30 seconds, and elongation at $72^{\circ} \mathrm{C}$ for 30 seconds. At the end of the last cycle, a melting curve was generated by starting fluorescence acquisition at $60^{\circ} \mathrm{C}$ and recording measurements at $0.3^{\circ} \mathrm{C}$ increments up to $95^{\circ} \mathrm{C}$.

A standard curve was generated for each amplicon by amplifying serial dilutions of a known quantity. PCR products for each gene were purified using a QIAquick PCR Purification Kit (Qiagen), quantified by measuring absorbance at $260 \mathrm{~nm}$ using a NanoDrop (ND-1000; Thermo Fisher Scientific), and diluted as described. Serial 10-fold dilutions for creating the standard curve were amplified in all real-time PCR runs. The standards and cDNA samples were then coamplified in the same reaction prepared from a master mix. Fluorescence was acquired at each cycle to determine the threshold cycle or the cycle during the log-linear phase of the reaction, at which fluorescence rose above the background for each sample. Final quantification was performed using StepOne ${ }^{\mathrm{TM}}$ quantification software. Expression of the target gene in each run was normalized to the internal standard glyceraldehyde-3-phosphate dehydrogenase $(G A P D H)$.

\section{Immunofluorescence staining}

Oocytes or embryos at the indicated developmental stage were fixed in PBS containing 4\% (w/v) paraformaldehyde (Wako Pure Chemical Industries, Osaka, Japan) for 20 minutes and then washed twice in PBS containing $0.1 \%(\mathrm{v} / \mathrm{v})$ Triton X100 (TXPBS) for 10 minutes each time. Samples were subsequently permeabilized in $0.2 \%$ (v/v) Triton X-100 in PBS for 30 minutes, incubated in Image-iT FX Signal Enhancer (Thermo Fisher Scientific) for 30 minutes, and washed twice in TXPBS for 10 minutes each time. Samples were blocked by incubation in $0.5 \%(\mathrm{w} / \mathrm{v})$ bovine serum albumin (BSA) and 1\% (w/v) skimmed milk in TXPBS for 1.5 hours and then washed in TXPBS for 5 minutes. The oocytes or embryos were incubated with an anti-YAP1 primary antibody (1:200, H00010413-MO1; Abnova, Taipei, Taiwan) in PBS supplemented with $0.5 \%$ (w/v) BSA and $0.05 \%$ (v/v) Triton X-100 at $4{ }^{\circ} \mathrm{C}$ for 1 hour.

Immunolabeled oocytes or embryos were washed four times in TXPBS for 15 minutes each time, and incubated at room temperature with Alexa Fluor 488-conjugated goat antimouse secondary antibody (1:400, A11029; Thermo Fisher Scientific) for 1 hour in PBS containing $0.5 \%(\mathrm{w} / \mathrm{v}) \mathrm{BSA}$ and $0.05 \%(\mathrm{v} / \mathrm{v})$ Triton X-100. Oocytes or embryos were then washed four times in TXPBS for 20 minutes each time and mounted onto slides in a drop of VECTASHIELD Mounting Medium with 4',6-diamidino-2-phenyndol (DAPI; Vector Laboratories, Burlingame, CA) for nuclear counterstaining. Fluorescent images were obtained using an inverted fluorescence microscope and digital camera systems (ECLIPSE Ti-U and DS-Fi2-L3; Nikon, Tokyo, Japan).

\section{Statistical analysis}

Percentage data for embryonic development was subjected to an arcsine transformation. The transformed values were analyzed using the one-way analysis of variance (ANOVA) or Kruskal-Wallis test, followed by multiple pairwise comparisons using the Tukey-Kramer or Scheffé method. The mRNA expression levels of YAP1 and LATS2 were analyzed using the Kruskal-Wallis test, followed by multiple pairwise comparisons using the Scheffé method. OCT-4 and SOX2 mRNA expression levels were analyzed by one-way ANOVA, following by multiple pairwise comparisons using the Fisher's PLSD or Tukey-Kramer method. A difference with $p<0.05$ was regarded as statistically significant for all tests.

\section{Results}

Temporal expression of YAP1 and LATS2 mRNA and protein in early embryos

YAP1 and LATS2 mRNA levels in the in vitro matured oocytes and embryos at various developmental stages are shown in Figure 1. YAPl mRNA level in the 1-cell stage 
A YAP1

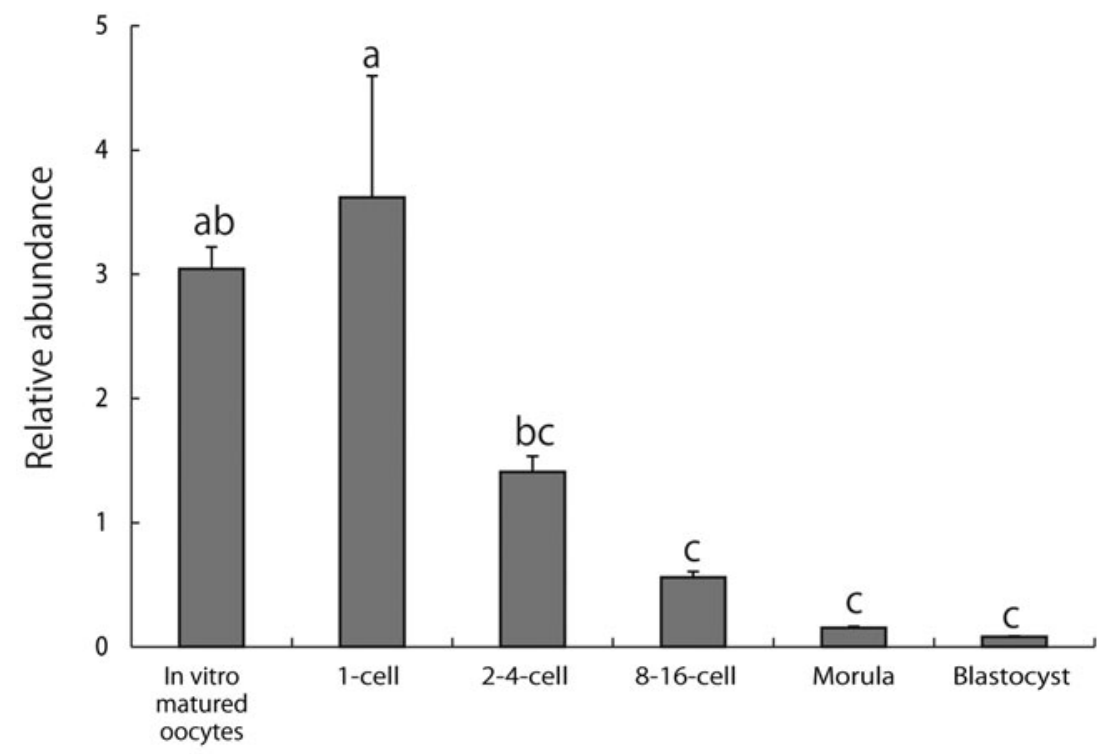

\section{B LATS2}

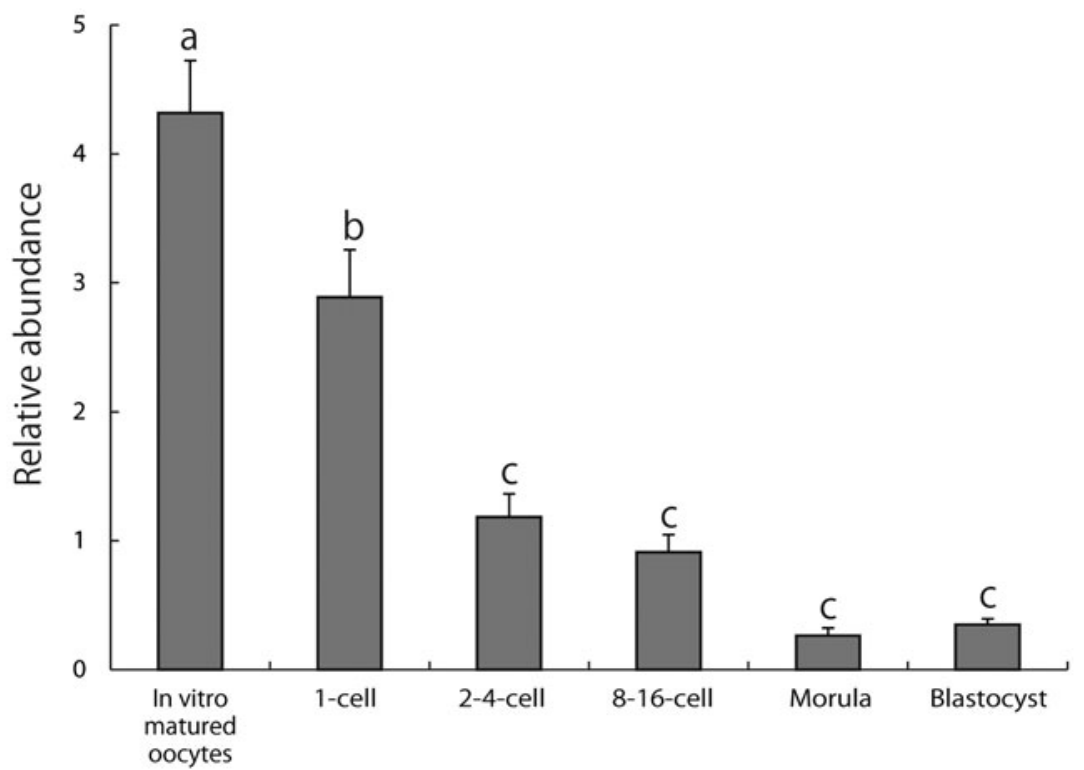

FIG. 1. Relative abundance (mean \pm SEM) of (A) YAP1 and (B) LATS2 transcripts in porcine in vitro matured oocytes and 1-cell to blastocyst stage embryos $(n=5) .{ }^{\mathrm{a}-\mathrm{c}}$ Different superscripts indicate significant differences $(p<0.05)$. LATS2, large tumor suppressor 2; SEM, standard error of the mean; YAP1, yes-associated protein 1 . embryos was significantly $(p<0.05)$ higher than that in the 2 cell to blastocyst stage embryos (Fig. 1A). YAPl transcript levels in the following 2-4-cell stage were decreased (Fig. 1A). LATS2 mRNA level in the in vitro matured oocytes was significantly $(p<0.05)$ higher than that in the 1 -cell to blastocyst stage embryos, and which the expression level was beginning to decline at the following 1-cell stage (Fig. 1B).

Temporal expression status of YAP1 protein was evaluated by immunofluorescence labeling (Fig. 2). Nuclear localization of the YAP1 protein was detected at the morula and blastocyst stage. In the blastocyst stage embryos, nuclear YAP1 signals were clearly observed in TE at least.

\section{Effect of siRNA injection on YAP1} and LATS2 expression

To evaluate the efficacy of YAP1 and LATS2 downregulation using RNA interference, YAP1 and LATS2 mRNA levels in uninjected, control siRNA-injected, and YAP1 or LATS2 siRNA-injected embryos at the 16-cell stage were investigated (Fig. 3). The relative abundance of YAP1 mRNA in YAP1 siRNA-injected embryos was significantly $(p<0.05)$ lower than that in uninjected and control siRNA-injected embryos (Fig. 3A). Similarly, LATS 2 mRNA level was significantly $(p<0.05)$ reduced in LATS2 siRNA-injected embryos compared to embryos subjected to control siRNA injection (Fig. 3B). LATS2 mRNA level in LATS2 siRNAinjected embryos was slightly $(p=0.07)$ lower than that in uninjected embryos (Fig. 3B).

\section{Effect of YAP1 or LATS2 downregulation on the development of porcine embryos}

We first evaluated the in vitro developmental competence of YAP1 siRNA-injected embryos (Table 2). No significant 

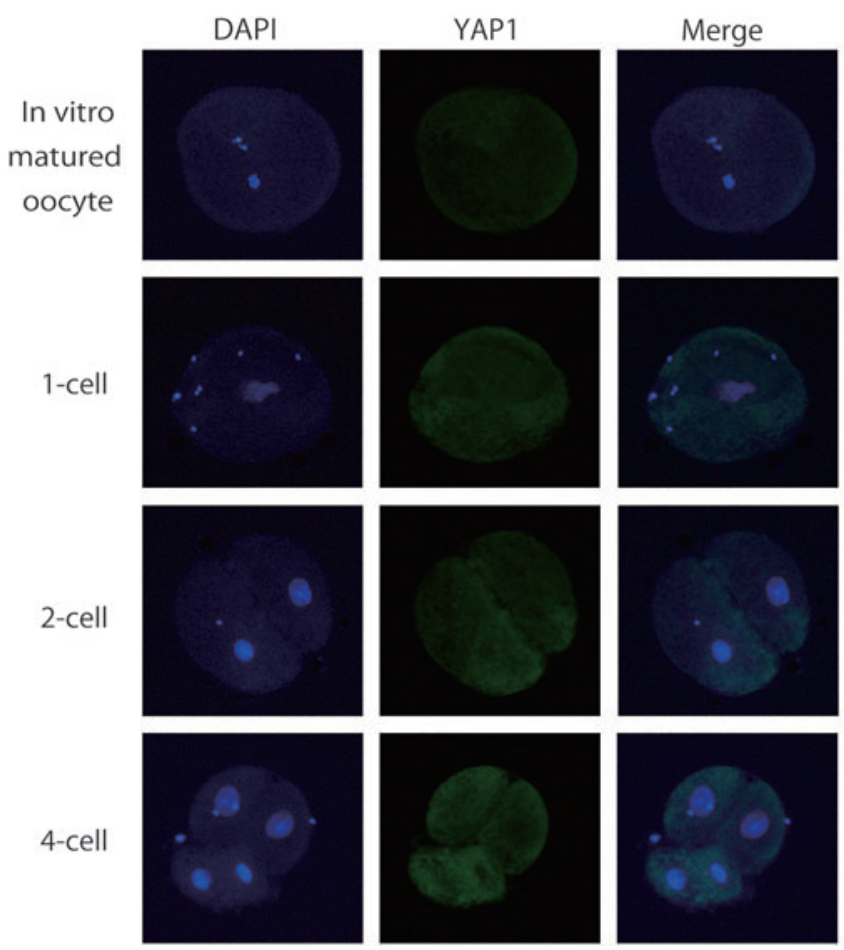
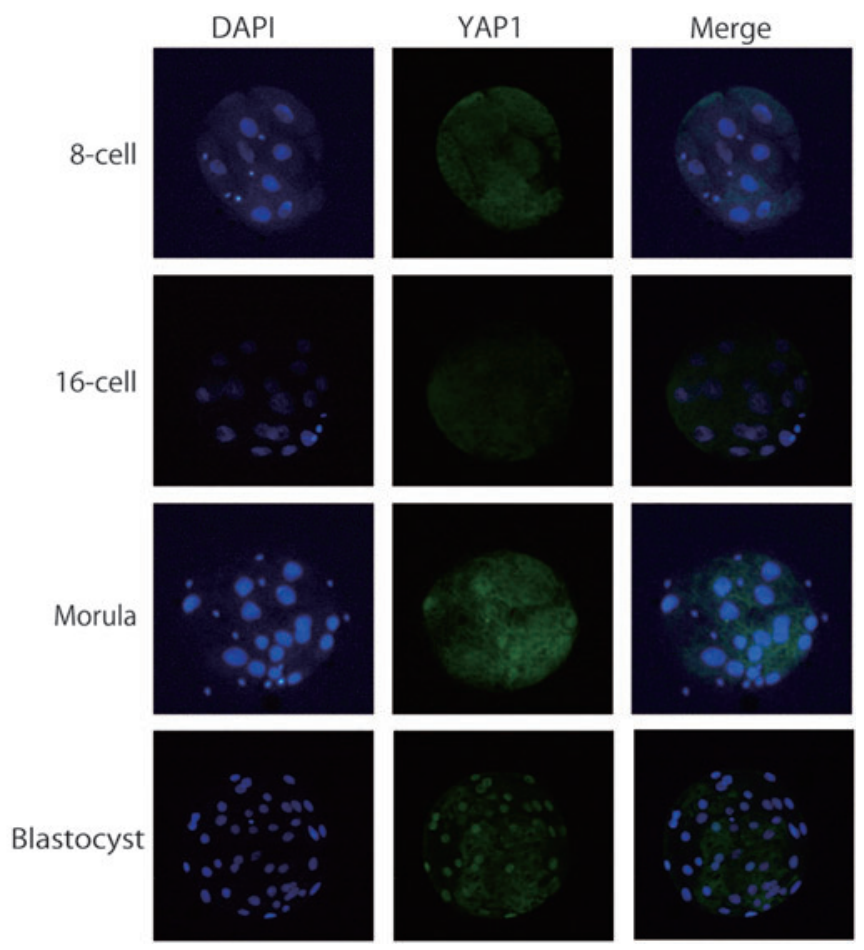

FIG. 2. Representative photographs of YAP1 protein expression in porcine in vitro matured oocytes and 1-cell to blastocyst stage embryos. The oocytes and embryos are labeled with DAPI (blue) and YAP1 (green). DAPI, 4',6-diamidino2-phenyndol. Color images are available online.

differences in the rate of development to the 2-cell $\leq$ embryos on day 2 were observed among the experimental groups. On day 3 , however, the rate of development to the 8-cell stage was significantly $(p<0.05)$ higher in uninjected embryos than in control siRNA-injected embryos. On day 4 , the rate of development to the 16-cell $\leq$ embryos was significantly $(p<0.05)$ higher in the uninjected group than in the YAP1 siRNAinjected and control siRNA-injected groups.

The rate of the morula stage development was significantly $(p<0.05)$ lower in YAP1 siRNA-injected embryos than in uninjected embryos, while there was no difference between uninjected and control siRNA-injected embryos. On day 5 , the rate of the blastocyst stage development was significantly $(p<0.05)$ lower in YAP1 siRNA-injected embryos $(0.5 \%)$ than in uninjected $(20.4 \%)$ and control siRNAinjected embryos $(15.9 \%)$.

The developmental competence of LATS2 siRNA-injected embryos is summarized in Table 3. No differences among experimental groups were observed until the 8-cell stage on day 3 . On day 4 , the rates of the 16 -cell $\leq$ and morula stage development were significantly $(p<0.05)$ lower in LATS2 siRNAinjected embryos than in uninjected and control siRNA-injected embryos. The number of embryos reaching the blastocyst stage (day 5) was also significantly $(p<0.05)$ lower in the LATS2 siRNA-injected group $(1.0 \%)$ than in the uninjected $(34.6 \%)$ and control siRNA-injected groups (24.2\%).

\section{Relative expression levels of the ICM/TE} segregation-related $m R N A$ transcripts in porcine embryos derived from YAP1 or LATS2 siRNA injection

$O C T-4$ and SOX2 transcript levels were analyzed at the 16cell stage to clarify the effects of YAP1 and LATS2 down- regulation on expression of genes involved in the ICM/TE segregation (Fig. 4). YAP1 siRNA injection significantly $(p<0.05)$ increased both OCT-4 and SOX2 expression levels (Fig. 4A). As shown in Figure 4B, although there was no difference in OCT-4 mRNA levels between uninjected and LATS2 siRNA-injected embryos, OCT-4 transcript level in LATS2 siRNA-injected embryos was significantly $(p<0.05)$ lower than that in control siRNA-injected embryos. Similarly, the expression level of SOX2 in LATS2-injected embryos was significantly $(p<0.05)$ lower than that in uninjected and control siRNA-injected embryos (Fig. 4B).

\section{Discussion}

It is well known that the Hippo pathway has important roles of the ICM/TE segregation in mice (Hirate et al., 2013; Nishioka et al., 2009). Lats $1 / 2$ kinases and the downstream effector Yap1 are the core components of the Hippo pathway. At the murine morula stage, the Hippo pathway is quiescent in the outer cells, and Yap1 is not phosphorylated by Lats $1 / 2$ kinases. Thus, Yap1 can localize to the nucleus and combine with Tead4 to induce expression of the TErelated genes such as $C d x 2$ (Home et al., 2012; Nishioka et al., 2008, 2009; Rayon et al., 2014; Yagi et al., 2007).

Conversely, the Hippo pathway is activated in the inner cells, resulting in Yap1 phosphorylation by Lats1/2 in the cytoplasm and inhibition of Yap1 nuclear translocation (Hirate et al., 2013; Nishioka et al., 2009). In this condition, the TE-related gene expression does not take place, and the inner cells adopt the ICM phenotype. Taken together, Yap1 and Lats1/2 are necessary for the segregation of the TE and ICM, respectively, in mice. In this study, we evaluated the functions of YAP1 and LATS2 in preimplantation porcine embryos using RNA interference. 


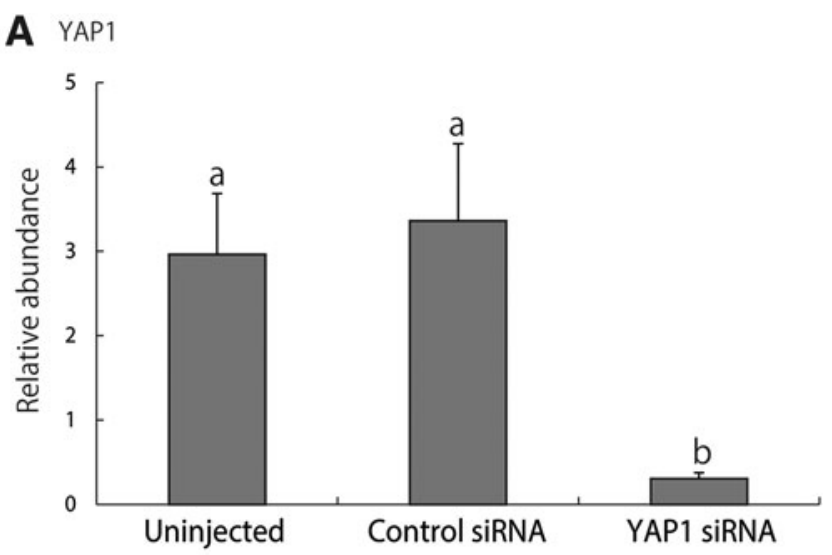

B LATS2

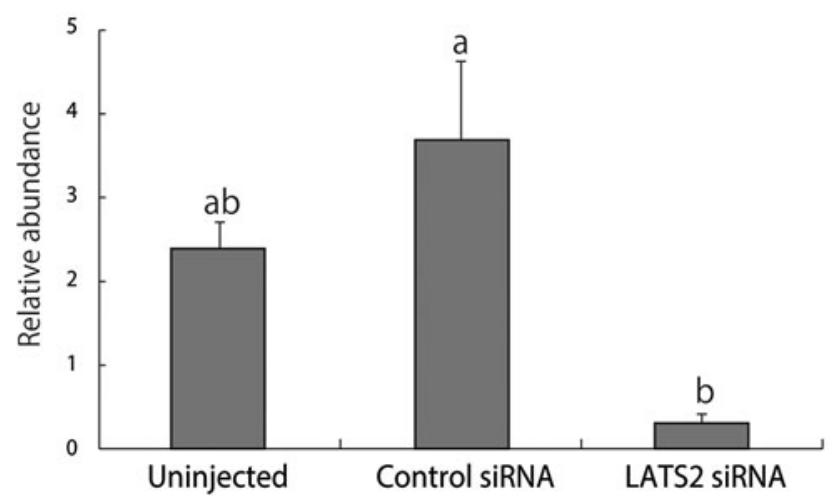

FIG. 3. Relative abundance (mean \pm SEM) of (A) YAP1 and (B) LATS2 transcripts at the 16-cell stage in uninjected $(n=5)$, control siRNA-injected $(n=5)$, and YAP1 (A) or LATS2 (B) siRNA-injected embryos $(n=5)$. ${ }^{\mathrm{a}, \mathrm{b}}$ Different superscripts indicate a significant difference $(p<0.05)$.

In mice, Yapl transcription levels are high from the oocyte to 2-cell stage and then decrease with development to the blastocyst stage (Yu et al., 2016). In the present study, YAP1 mRNA expression in porcine in vitro matured oocytes and embryos was detected at all developmental stages. Similar to the case with mice, YAP1 mRNA levels in the oocytes and embryos just after fertilization were the highest in pigs. On the contrary, nuclear signals of YAP1 protein in porcine embryos were detected from the morula stage, and they were clearly observed in TE at the blastocyst stage. Our previous research has shown that TEAD4 protein was in nuclei of porcine embryos from the 16-cell to blastocyst stage (Emura et al., 2019). These findings suggest that YAP1 mRNA is transcribed at early stages, and is progressively translated and shuttled to the nucleus where it cooperates with TEAD4 to activate genes required for preimplantation development at late stages.

Although LATS2 mRNA expression was detected at all developmental stages in porcine oocytes and embryos, LATS2 mRNA expression was higher in the in vitro matured oocytes and 1-cell stage embryos than at the other developmental stages, similar to the expression pattern of YAP1 mRNA. While Lats 2 mRNA expression and enzyme activity are well described in murine oocytes and embryos (Nishioka et al., 2009), expression status in porcine oocytes and preimplantation embryos was unknown. In the present study, we demonstrate that both LATS2 and YAP1 are expressed in porcine oocytes and preimplantation embryos, and that the Hippo pathway may play a role in functional regulation of gene expression involved in the ICM/TE segregation of porcine embryos.

Interestingly, our study showed that downregulation of YAP1 transcript allowed porcine embryos to develop to the morula stage, but strongly inhibited blastocyst formation. In murine embryos, $C d x 2$ expression by Tead4-Yap1 complex in the outer cells of morulae is important for TE segregation (Home et al., 2012; Nishioka et al., 2008, 2009; Rayon et al., 2014; Yagi et al., 2007).

Our previous study has found porcine embryos with TEAD4 downregulated cannot form blastocysts, similar to the YAP1 downregulation in this study (Emura et al., 2019). Therefore, it is possible that the TEAD4-YAP1 complex is essential for TE differentiation of porcine embryos. However, TEAD4 downregulation does not affect CDX2 expression (Emura et al., 2019), and CDX2 is dispensable for TE segregation in porcine embryos (Bou et al., 2017). Further studies are necessary to identify the downstream factors of the TEAD4-YAP1 complex in porcine embryos. On the contrary, LATS2 downregulation inhibited porcine embryo development before the morula stage. This result indicates that LATS2 regulates the preimplantation development of porcine embryos in addition to segregating the ICM/TE lineages from the morula to blastocyst stage.

Oct-4 is a marker for pluripotency as possessed by ESCs (Niwa et al., 2000; Yeom et al., 1996). In murine embryos, Oct-4 is required for ICM formation, but is dispensable for TE segregation (Nichols et al., 1998). In porcine blastocyst stage embryos, OCT-4 is expressed in both ICM and TE (du Puy et al., 2011; Fujii et al., 2013; Kirchhof et al., 2000), and our previous research has indicated that OCT-4 expression

Table 2. Effect of Yes-Associated Protein 1 siRnA Injection on IN Vitro Development of Porcine Embryos

$$
\text { No. }(\%) * \text { of embryos developed to }
$$

\begin{tabular}{|c|c|c|c|c|c|c|}
\hline \multirow[b]{2}{*}{ Treatment } & \multirow[b]{2}{*}{ No. of embryos cultured } & \multirow{2}{*}{$\begin{array}{c}\text { Day } 2 \\
2 \text {-cell } \leq\end{array}$} & \multirow{2}{*}{$\begin{array}{l}\text { Day } 3 \\
\text { 8-cell }\end{array}$} & \multicolumn{2}{|c|}{ Day 4} & \multirow{2}{*}{$\frac{\text { Day } 5}{\text { Blastocyst }}$} \\
\hline & & & & 16 -cell $\leq$ & Morula & \\
\hline & 196 & $138(70.4)$ & $61(31.1)^{\mathrm{a}}$ & $104(53.1)^{\mathrm{a}}$ & $37(18.9)^{\mathrm{a}}$ & $40(20.4)^{\mathrm{a}}$ \\
\hline Control & 195 & $119(61.0)$ & $40(20.5)^{\mathrm{b}}$ & $81(41.5)^{\mathrm{b}}$ & $27(13.8)^{\mathrm{ab}}$ & $31(15.9)^{\mathrm{a}}$ \\
\hline YAP1 siRNA & 192 & $118(61.5)$ & $44(22.9)^{\mathrm{ab}}$ & $60(31.3)^{b}$ & $20(10.4)^{b}$ & $1(0.5)^{b}$ \\
\hline
\end{tabular}

Experiments were replicated five times.

*Percentages of the number of embryos cultured.

${ }^{\mathrm{a}, \mathrm{b}}$ Values with different superscripts within each column differ significantly $(p<0.05)$. 
Table 3. Effect of Large Tumor Suppressor 2 siRnA Injection on In Vitro Development of Porcine Embryos

\begin{tabular}{|c|c|c|c|c|c|c|}
\hline \multirow[b]{3}{*}{ Treatment } & \multirow{3}{*}{$\begin{array}{c}\text { No. of embryos } \\
\text { cultured }\end{array}$} & \multicolumn{5}{|c|}{ No. $(\%)^{*}$ of embryos developed to } \\
\hline & & \multirow{2}{*}{$\begin{array}{c}\text { Day } 2 \\
\text {-cell } \leq\end{array}$} & \multirow{2}{*}{$\begin{array}{c}\text { Day } 3 \\
\text {-cell }\end{array}$} & \multicolumn{2}{|c|}{ Day 4} & \multirow{2}{*}{$\frac{\text { Day } 5}{\text { Blastocyst }}$} \\
\hline & & & & 16 -cell $\leq$ & Morula & \\
\hline Uninjected & 211 & $152(72.0)$ & $85(40.3)$ & $115(54.5)^{\mathrm{a}}$ & $47(22.3)^{\mathrm{a}}$ & $73(34.6)^{\mathrm{a}}$ \\
\hline Control siRNA & 207 & $138(66.7)$ & $69(33.3)$ & $87(42.0)^{\mathrm{a}}$ & $37(17.9)^{\mathrm{a}}$ & $50(24.2)^{\mathrm{a}}$ \\
\hline LATS2 siRNA & 205 & $137(66.8)$ & $84(41.0)$ & $57(27.8)^{b}$ & $4(2.0)^{\mathrm{b}}$ & $2(1.0)^{\mathrm{b}}$ \\
\hline
\end{tabular}

Experiments were replicated five times.

*Percentages of the number of embryos cultured.

${ }^{\mathrm{a}, \mathrm{b}}$ Values with different superscripts within each column differ significantly $(p<0.05)$.

is essential for porcine TE segregation (Emura et al., 2016; Sakurai et al., 2013). Therefore, OCT-4 functions in the formation of both ICM and TE in porcine embryos.

Lacking maternal Yapl in murine embryos increased expression of ICM-related genes, such as Oct- 4 and $\mathrm{Na}-$ nog (Yu et al., 2016). The Tead4-Yap1 complex is not formed in the nucleus in cells with Yapl deletion, so it is possible that expression of the target gene $C d x 2$ is decreased under such conditions. Moreover, $C d x 2$ downregulation induces Oct-4 expression in blastomeres. In addition, Lats1/2 downregulation in mice reduces phosphorylated Yap1, resulting in transition of Yap1 into the nucleus
(Lorthongpanich et al., 2013; Nishioka et al., 2009). As a result, Cdx2 is expressed in every cell while Oct-4 expression is unchanged (Lorthongpanich et al., 2013; Nishioka et al., 2009).

In the present study, YAP1 downregulation led to $O C T-4$ upregulation as in murine embryos. Furthermore, LATS2 downregulation decreased $O C T-4$ expression in porcine embryos. These results imply that YAP1 and LATS2 regulate $O C T-4$ expression in porcine preimplantation embryos. However, TEAD4 downregulating in porcine embryos has no influence on $O C T-4$ expression despite findings that Tead4-deficient murine embryos express high levels of Oct-

A YAP1 downregulation
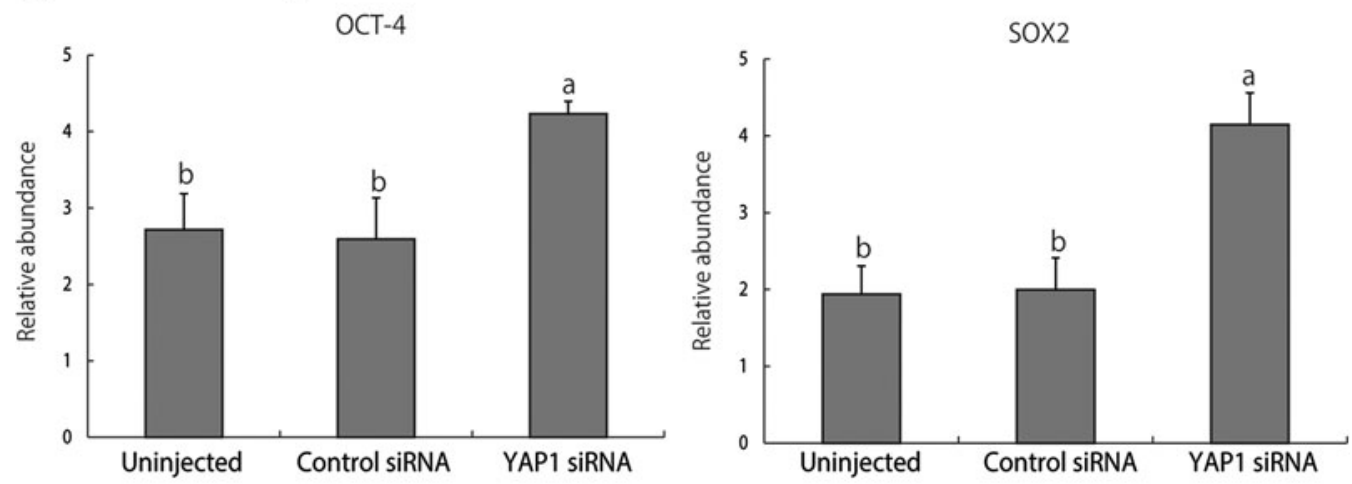

B LATS2 downregulation
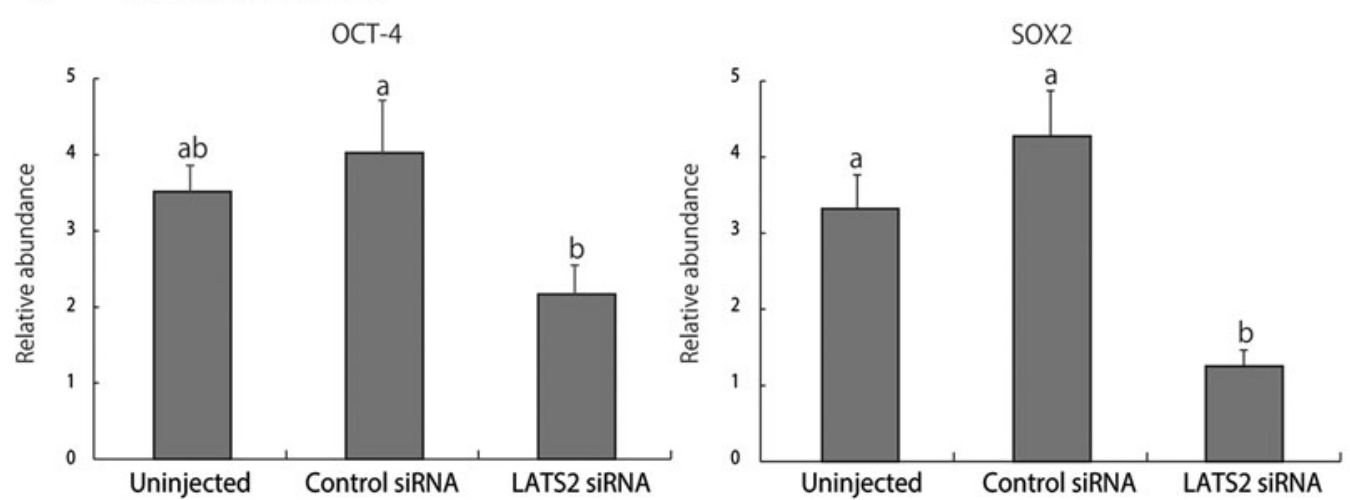

FIG. 4. (A) Relative abundance (mean \pm SEM) of $O C T$-4 and SOX2 transcripts at the 16-cell stage in uninjected $(n=5)$, control siRNA-injected $(n=5)$, and YAP1 siRNA-injected embryos $(n=5)$. ${ }^{\mathrm{a}, \mathrm{b}}$ Different superscripts indicate a significant difference $(p<0.05)$. (B) Relative abundance (mean \pm SEM) of OCT-4 and SOX2 transcripts at the 16-cell stage in uninjected $(n=5)$, control siRNA-injected $(n=5)$ and LATS2 siRNA-injected embryos $(n=5)$. ${ }^{\mathrm{a}, \mathrm{b}}$ Different superscripts indicate a significant difference $(p<0.05)$. OCT-4, POU class 5 homeobox 1; SOX2, SRY-related HMG-box gene 2. 
4 (Emura et al., 2019; Yagi et al., 2007). Thus, in porcine embryos, YAP1 controls OCT-4 expression independently from TEAD4.

Sox2 is also a marker for pluripotency and interacts with Oct-4 for forming the Oct-Sox enhancer in ESCs (Kuroda et al., 2005; Masui et al., 2007; Okumura-Nakanishi et al., 2005). In murine embryos, Sox 2 is essential for ICM formation (Avilion et al., 2003), and Sox 2 expression is absent in Lats1/2-downregulated embryos (Lorthongpanich et al., 2013). Conversely, lacking either Yap1 or Tead4 increases ectopic Sox 2 expression (Frum et al., 2018; Wicklow et al., 2014). Taken together, Tead4 and Yap1 contribute to TE segregation in murine embryos through Sox2 repression.

In the present study, SOX2 expression was upregulated by YAP1 downregulation in porcine embryos. In contrast, LATS2 downregulation impaired SOX2 expression. Our recent study also has shown that TEAD4 negatively regulates SOX2 expression in porcine embryos (Emura et al., 2019). These results suggest that the molecular mechanisms for regulation of $S O X 2$ expression in porcine embryos are similar to those in murine embryos.

In conclusion, we demonstrated that YAP1 and LATS2 are important for early porcine embryo development and expression of downstream genes involved in the segregation of ICM and TE lineages. YAP1 downregulation inhibited blastocyst formation and increased expression of OCT-4 and SOX2. In addition, LATS2-downregulated embryos could not develop to the morula stage and exhibited reduced $O C T-4$ and SOX2 expression. This is the first time to indicate the necessity of YAP1 and LATS2 and the findings about the mechanism of early lineage segregation in porcine embryos. This study showed the possibility that the Hippo pathway plays an important role in the ICM/TE segregation of porcine embryos; however, further studies are required to elucidate the functions of the Hippo pathway in porcine embryogenesis.

\section{Author Disclosure Statement} exist.

The authors declare that no conflicting financial interests

\section{Funding Information}

This work was supported by JSPS KAKENHI grant no. 18J20102.

\section{References}

Avilion, A.A., Nicolis, S.K., Pevny, L.H., Perez, L., Vivian, N., and Lovell-Badge, R. (2003). Multipotent cell lineages in early mouse development depend on SOX2 function. Genes Dev. 17, 126-140.

Bou, G., Liu, S., Sun, M., Zhu, J., Xue, B., Guo, J., Zhao, Y., Qu, B., Weng, X., Wei, Y., Lei, L., and Liu, Z. (2017). CDX2 is essential for cell proliferation and polarity in porcine blastocysts. Development 144, 1296-1306.

Cockburn, K., Biechele, S., Garner, J., and Rossant, J. (2013). The Hippo pathway member Nf2 is required for inner cell mass specification. Curr. Biol. 23, 1195-1201.

du Puy, L., Lopes, S.M., Haagsman, H.P., and Roelen, B.A. (2011). Analysis of co-expression of OCT4, NANOG and SOX2 in pluripotent cells of the porcine embryo, in vivo and in vitro. Theriogenology 75, 513-526.
Emura, N., Sakurai, N., Takahashi, K., Hashizume, T., and Sawai, K. (2016). OCT-4 expression is essential for the segregation of trophectoderm lineages in porcine preimplantation embryos. J. Reprod. Dev. 62, 401-408.

Emura, N., Takahashi, K., Saito, Y., and Sawai, K. (2019). The necessity of TEAD4 for early development and gene expression involved in differentiation in porcine embryos. J. Reprod. Dev 65, 361-368.

Evans, M.J., and Kaufman, M.H. (1981). Establishment in culture of pluripotential cells from mouse embryos. Nature 292, 154-156.

Frum, T., Murphy, T.M., and Ralston, A. (2018). HIPPO signaling resolves embryonic cell fate conflicts during establishment of pluripotency in vivo. Elife 7, e42298.

Fujii, T., Sakurai, N., Osaki, T., Iwagami, G., Hirayama, H., Minamihashi, A., Hashizume, T., and Sawai, K. (2013). Changes in the expression patterns of the genes involved in the segregation and function of inner cell mass and trophectoderm lineages during porcine preimplantation development. J. Reprod. Dev. 59, 151-158.

Hirate, Y., Hirahara, S., Inoue, K., Suzuki, A., Alarcon, V.B., Akimoto, K., Hirai, T., Hara, T., Adachi, M., Chida, K., Ohno, S., Marikawa, Y., Nakao, K., Shimono, A., and Sasaki, H. (2013). Polarity-dependent distribution of angiomotin localizes Hippo signaling in preimplantation embryos. Curr. Biol. 23, 1181-1194.

Home, P., Saha, B., Ray, S., Dutta, D., Gunewardena, S., Yoo, B., Pal, A., Vivian, J.L., Larson, M., Petroff, M., Gallagher, P.G., Schulz, V.P., White, K.L., Golos, T.G., Behr, B., and Paul, S. (2012). Altered subcellular localization of transcription factor TEAD4 regulates first mammalian cell lineage commitment. Proc. Natl. Acad. Sci. U. S. A. 109, 7362-7367.

Kikuchi, K., Onishi, A., Kashiwazaki, N., Iwamoto, M., Noguchi, J., Kaneko, H., Akita, T., and Nagai, T. (2002). Successful piglet production after transfer of blastocysts produced by a modified in vitro system. Biol. Reprod. 66, 1033-1041.

Kirchhof, N., Carnwath, J.W., Lemme, E., Anastassiadis, K., Scholer, H., and Niemann, H. (2000). Expression pattern of Oct-4 in preimplantation embryos of different species. Biol. Reprod. 63, 1698-1705.

Kuroda, T., Tada, M., Kubota, H., Kimura, H., Hatano, S.Y., Suemori, H., Nakatsuji, N., and Tada, T. (2005). Octamer and Sox elements are required for transcriptional cis regulation of Nanog gene expression. Mol. Cell Biol. 25, 2475-2485.

Lorthongpanich, C., Messerschmidt, D.M., Chan, S.W., Hong, W., Knowles, B.B., and Solter, D. (2013). Temporal reduction of LATS kinases in the early preimplantation embryo prevents ICM lineage differentiation. Genes Dev. 27, 14411446.

Martin, G.R. (1981). Isolation of a pluripotent cell line from early mouse embryos cultured in medium conditioned by teratocarcinoma stem cells. Proc. Natl. Acad. Sci. U. S. A. 78, 7634-7638.

Masui, S., Nakatake, Y., Toyooka, Y., Shimosato, D., Yagi, R., Takahashi, K., Okochi, H., Okuda, A., Matoba, R., Sharov, A.A., Ko, M.S., and Niwa, H. (2007). Pluripotency governed by Sox 2 via regulation of Oct $3 / 4$ expression in mouse embryonic stem cells. Nat. Cell Biol. 9, 625-635.

Nagai, T., Takahashi, T., Masuda, H., Shioya, Y., Kuwayama, M., Fukushima, M., Iwasaki, S., and Hanada, A. (1988). Invitro fertilization of pig oocytes by frozen boar spermatozoa. J. Reprod. Fertil. 84, 585-591.

Nichols, J., Zevnik, B., Anastassiadis, K., Niwa, H., KleweNebenius, D., Chambers, I., Scholer, H., and Smith, A. (1998). 
Formation of pluripotent stem cells in the mammalian embryo depends on the POU transcription factor Oct4. Cell 95, 379391.

Nishioka, N., Inoue, K., Adachi, K., Kiyonari, H., Ota, M., Ralston, A., Yabuta, N., Hirahara, S., Stephenson, R.O., Ogonuki, N., Makita, R., Kurihara, H., Morin-Kensicki, E.M., Nojima, H., Rossant, J., Nakao, K., Niwa, H., and Sasaki, H. (2009). The Hippo signaling pathway components Lats and Yap pattern Tead4 activity to distinguish mouse trophectoderm from inner cell mass. Dev. Cell 16, 398-410.

Nishioka, N., Yamamoto, S., Kiyonari, H., Sato, H., Sawada, A., Ota, M., Nakao, K., and Sasaki, H. (2008). Tead4 is required for specification of trophectoderm in pre-implantation mouse embryos. Mech. Dev. 125, 270-283.

Niwa, H., Miyazaki, J., and Smith, A.G. (2000). Quantitative expression of Oct-3/4 defines differentiation, dedifferentiation or self-renewal of ES cells. Nat. Genet. 24, 372-376.

Okumura-Nakanishi, S., Saito, M., Niwa, H., and Ishikawa, F. (2005). Oct-3/4 and Sox 2 regulate Oct-3/4 gene in embryonic stem cells. J. Biol. Chem. 280, 5307-5317.

Pedersen, R.A., Wu, K., and Balakier, H. (1986). Origin of the inner cell mass in mouse embryos: Cell lineage analysis by microinjection. Dev. Biol. 117, 581-595.

Petters, R.M., and Wells, K.D. (1993). Culture of pig embryos. J. Reprod. Fertil. Suppl. 48, 61-73.

Rayon, T., Menchero, S., Nieto, A., Xenopoulos, P., Crespo, M., Cockburn, K., Canon, S., Sasaki, H., Hadjantonakis, A.K., de la Pompa, J.L., Rossant, J., and Manzanares, M. (2014). Notch and hippo converge on $\mathrm{Cdx} 2$ to specify the trophectoderm lineage in the mouse blastocyst. Dev. Cell 30, 410-422.

Sakurai, N., Fujii, T., Hashizume, T., and Sawai, K. (2013). Effects of downregulating oct-4 transcript by RNA interference on early development of porcine embryos. J. Reprod. Dev. 59, 353-360.

Suzuki, C., and Yoshioka, K. (2006). Effects of amino acid supplements and replacement of polyvinyl alcohol with bovine serum albumin in porcine zygote medium. Reprod. Fertil. Dev. 18, 789-795.

Tanaka, S., Kunath, T., Hadjantonakis, A.K., Nagy, A., and Rossant, J. (1998). Promotion of trophoblast stem cell proliferation by FGF4. Science 282, 2072-2075.
Wicklow, E., Blij, S., Frum, T., Hirate, Y., Lang, R.A., Sasaki, H., and Ralston, A. (2014). HIPPO pathway members restrict SOX2 to the inner cell mass where it promotes ICM fates in the mouse blastocyst. PLoS Genet. 10, e1004618.

Yagi, R., Kohn, M.J., Karavanova, I., Kaneko, K.J., Vullhorst, D., DePamphilis, M.L., and Buonanno, A. (2007). Transcription factor TEAD4 specifies the trophectoderm lineage at the beginning of mammalian development. Development 134 , 3827-3836.

Yamanaka, Y., Ralston, A., Stephenson, R.O., and Rossant, J. (2006). Cell and molecular regulation of the mouse blastocyst. Dev. Dyn. 235, 2301-2314.

Yeom, Y.I., Fuhrmann, G., Ovitt, C.E., Brehm, A., Ohbo, K., Gross, M., Hubner, K., and Scholer, H.R. (1996). Germline regulatory element of Oct-4 specific for the totipotent cycle of embryonal cells. Development 122, 881-894.

Yu, C., Ji, S.Y., Dang, Y.J., Sha, Q.Q., Yuan, Y.F., Zhou, J.J., Yan, L.Y., Qiao, J., Tang, F., and Fan, H.Y. (2016). Oocyteexpressed yes-associated protein is a key activator of the early zygotic genome in mouse. Cell Res. 26, 275-287.

Yu, F.X., Zhang, Y., Park, H.W., Jewell, J.L., Chen, Q., Deng, Y., Pan, D., Taylor, S.S., Lai, Z.C., and Guan, K.L. (2013). Protein kinase A activates the Hippo pathway to modulate cell proliferation and differentiation. Genes Dev. 27, 12231232 .

Zhao, B., Wei, X., Li, W., Udan, R.S., Yang, Q., Kim, J., Xie, J., Ikenoue, T., Yu, J., Li, L., Zheng, P., Ye, K., Chinnaiyan, A., Halder, G., Lai, Z.C., and Guan, K.L. (2007). Inactivation of YAP oncoprotein by the Hippo pathway is involved in cell contact inhibition and tissue growth control. Genes Dev. 21, 2747-2761.

Address correspondence to: Ken Sawai United Graduate School of Agricultural Sciences Iwate University Ueda $3-18-8$ Morioka, Iwate 020-8550 Japan

E-mail: kensawai@iwate-u.ac.jp 